Tracz Mariola

Akademia Pedagogiczna, Kraków

\title{
Treści z zakresu geografii przemysłu w podstawach programowych i wybranych programach nauczania oraz podręcznikach do geografii na poziomie gimnazjum i szkoły ponadgimnazjalnej
}

W celu określenia zakresu treści z geografii przemysłu w programach nauczania i podręcznikach do geografii w gimnazjum i szkole ponadgimnazjalnej zastosowano metodę analizy porównawczej. Celem badań było wskazanie czynników kształtujących dobór oraz sposoby przedstawiania treści z zakresu geografii przemysłu. Analizę ilościową i jakościową przeprowadzono na podstawie kwerendy aktualnie obowiązujących programów nauczania i podręczników do geografii dla gimnazjum i szkoły ponadgimnazjalnej (liceum ogólnokształcącego, liceum profilowanego, technikum). Programy nauczania geografii i podręczniki wyselekcjonowano na podstawie Bibliografii Dydaktyki Geografii T. IV, zasobów biblioteki IG AP w Krakowie oraz stron internetowych MEN i stron poszczególnych wydawnictw. Łącznie na poziomie gimnazjum przeanalizowano 15 programów nauczania geografii (z 22 dopuszczonych do użytku przez MEN) i 15 podręczników zatwierdzonych. Natomiast na poziomie szkoły ponadgimnazjalnej zbadano 10 programów nauczania (z 19 wpisanych na listę MEN) i 10 podręczników do nauczania geografii.

Należy nadmienić, iż po zmianie systemu szkolnego w 1999 roku zasadniczy kurs geografii realizowany jest $\mathrm{w}$ gimnazjum w wymiarze 4 godzin w cyklu kształcenia w ciągu trzech lat, tj. ok. 120 godz., oraz w szkole ponadgimnazjalnej w wymiarze 3 godz. w ciagu trzech lat, tj. ok. 90 godz. Z tego wynika, że ilość czasu, którą może nauczyciel geografii poświecić na realizację tematyki z geografii przemysłu nie jest duża. Najczęściej jest to od 1 do 3 godz. lekcyjnych tygodniowo. Treści z geografii przemysłu na poziomie gimnazjum i szkoły ponadgimnazjalnej występują na ogół w II i III klasie. Dlatego istotne jest, czy treści te w programach nauczania i podręcznikach szkolnych prezentowane są zgodnie ze współczesnymi tendencjami w kształceniu geograficznym oraz stanem dorobku naukowego geografii przemysłu.

Przeanalizujmy zatem jak te założenia realizowane są w odniesieniu do treści z geografii przemysłu w podstawie programowej oraz wybranych programach nauczania i podręcznikach geografii.

Autorzy podstawy programowej z geografii założyli, że poznawanie wybranych zagadnień geograficznych, w tym treści z geografii przemysłu, odbywać się winno według wybranych problemów w ujęciu holistycznym (Podstawa programowa 2001, 2002). Zgodnie $\mathrm{z}$ celami nauczania zapisanymi w podstawie programowej, uczniowie gimnazjum $\mathrm{w}$ kursie z geografii z zakresu tematyki dotyczącej przemysłu powinni: 
- zainteresować się szeroko rozumianą przestrzenią i funkcjonowaniem w niej m.in. działalności przemysłowej w odniesieniu do własnego regionu, terytorium Polski, Europy i świata,

- kształtować poczucie odpowiedzialności za środowisko geograficzne, gotowość uczestnictwa w rozwiązywaniu problemów, m.in. związanych ze stanem i rozwojem przemysłu w lokalnej społeczności.

Z kolei w szkole ponadgimnazjalnej cele nauczania obejmuja:

- rozszerzenie wiedzy niezbędnej do zrozumienia istoty zjawisk oraz charakteru i dynamiki procesów zachodzących w środowisku geograficznym w skali lokalnej, krajowej, wielkich regionów i świata, m.in. w odniesieniu do działalności przemysłowej,

- poznanie, zrozumienie i interpretowanie związków przyczynowo-skutkowych i funkcjonalnych w rozwoju przemysłu w różnych skalach przestrzennych i czasowych,

- zrozumienie złożoności świata, współzależności jego poszczególnych elementów i gotowości do udziału w jego przekształcaniu zgodnie z zasadą zrównoważonego rozwoju.

$\mathrm{Z}$ analizy podstawy programowej wynika, iż treści z geografii przemysłu występują zarówno na poziomie gimnazjum, jak i szkoły ponadgimnazjalnej (tab. 1). W gimnazjum uczniowie są wprowadzani w system pojęć z geografii przemysłu niezbędnych dla kursu geografii w szkole ponadgimnazjalnej przez prezentacje wybranej tematyki z geografii przemysłu w odniesieniu do kraju ojczystego i wybranych regionów świata. Ponadto uczniowie gimnazjum rozwijają umiejętności związane z odczytywaniem informacji zawartych w różnych źródłach, w tym z roczników statystycznych, map tematycznych - mapa gospodarcza, przemysł wydobywczy i przetwórczy itp. Z kolei w szkole ponadgimnazjalnej główny nacisk kładziony jest na poznanie i zrozumienie procesów gospodarczych oraz ich powiązania w skali lokalnej, regionalnej i globalnej. Uczniowie są zachęcani do badania i rozwijania wiedzy i jej rozumienia, formułowania prawidłowości i stosowania teorii wyjaśniających

Tabela 1. Treści z zakresu geografii przemysłu

$\mathrm{w}$ podstawie programowej w gimnazjum i szkole ponadgimnazjalnej

\begin{tabular}{|c|c|}
\hline Gimnazjum & $\begin{array}{c}\text { Szkoła ponadgimnazjalna } \\
\text { (liceum ogólnoksztalcące, } \\
\text { liceum profilowane, technikum) }\end{array}$ \\
\hline Interakcja Ziemia - człowiek & $\begin{array}{l}\text { Funkcjonalne i przestrzenne powiązania oraz wzajemne } \\
\text { zależności w systemie człowiek-przyroda-gospodarka }\end{array}$ \\
\hline Gospodarowanie zasobami naturalnymi & $\begin{array}{l}\text { Świat w fazie przemian społecznych, gospodarczych i } \\
\text { politycznych. Modernizacja, restrukturyzacja, globalizacja }\end{array}$ \\
\hline $\begin{array}{l}\text { Współczesne przemiany gospodarcze, } \\
\text { społeczne, polityczne na kontynentach } \\
\text { i wybranych państwach }\end{array}$ & $\begin{array}{l}\text { Konflikty zbrojne i inne zagrożenia społeczno-ekono- } \\
\text { miczne }\end{array}$ \\
\hline $\begin{array}{l}\text { Potencjał naturalny i ludnościowy, } \\
\text { gospodarczy i kulturowy Polski } \\
\text { Polska na tle Europy i świata } \\
\text { Problemy integracyjne na świecie, } \\
\text { w Europie i w Polsce }\end{array}$ & $\begin{array}{l}\text { Procesy przechodzenia od izolacji do integracji: współpra- } \\
\text { ca miedzy społeczeństwami; procesy integracyjne i dez- } \\
\text { integracyjne w Europie (ze szczególnym uwzględnieniem } \\
\text { Polski); euroregiony i miasta (gminy) „,bliźniacze” jako } \\
\text { przykład współpracy międzynarodowej na szczeblu regio- } \\
\text { nalnym i lokalnym }\end{array}$ \\
\hline
\end{tabular}

Źródło: Podstawa programowa 2002 
oraz zainteresowania własnym otoczeniem i zróżnicowaniem procesów społeczno-gospodarczych zachodzących na Ziemi, a będących wynikiem zachodzących przemian - globalizacji, integracji.

$\mathrm{W}$ gimnazjum tematyka $\mathrm{z}$ geografii przemysłu jest najszerzej prezentowana $\mathrm{w}$ następujących hasłach: gospodarowanie zasobami naturalnymi Ziemi, współczesne przemiany gospodarcze, społeczne i polityczne na kontynentach i wybranych państwach oraz potencjał gospodarczy i kulturowy Polski. Natomiast w szkole ponadgimnazjalnej treści z zakresu geografii przemysłu występują w hasłach: świat w fazie przemian społecznych, gospodarczych i politycznych, modernizacja, restrukturyzacja, globalizacja, procesy przechodzenia od izolacji do integracji i dezintegracji w Europie (ze szczególnym uwzględnieniem Polski); euroregiony i miasta (gminy) „bliźniacze” jako przykład współpracy międzynarodowej na szczeblu regionalnym i lokalnym. Treści zawarte w podstawie programowej wykazują zgodność z aktualnym stanem geografii jako nauki i uwzględniają najnowsze trendy dydaktyki geografii (Piskorz 1999, Pulinowa 2005). Duży stopień ogólności zapisu podstawy programowej powoduje jednak, że autorskie programy nauczania oraz podręczniki szkolne zawierają różną pod względem zakresu treści tematykę z geografii, w tym i z geografii przemysłu (tab. 2, tab. 3).

Tabela 2. Tematyka z geografii przemysłu w wybranych podręcznikach geografii do gimnazjum

\begin{tabular}{|c|c|}
\hline Podręcznik & Treści z geografii przemysłu \\
\hline $\begin{array}{l}\text { Czerny M., } \\
\text { Czerny A. } 2000\end{array}$ & $\begin{array}{l}\text { Industrializacja } \\
\text { Anglia kolebka przemysłu } \\
\text { Rozwój przemysłu ciężkiego } \\
\text { Zagłębie Ruhry } \\
\text { Gdzie rozwija się przemysł }\end{array}$ \\
\hline $\begin{array}{l}\text { Dobosik, Kardas, } \\
\text { Modzelewska } 1999\end{array}$ & $\begin{array}{l}\text { Wpływ przemysłu na środowisko przyrodnicze } \\
\text { Funkcje przemysłu } \\
\text { Czynniki lokalizacji przemysłu } \\
\text { Tworzenie się okręgów przemysłowych } \\
\text { Rozwój i rozmieszczenie przemysłu wysokiej technologii }\end{array}$ \\
\hline $\begin{array}{l}\text { Krynicka-Tarnacka, } \\
\text { Wnuk, Wojtkowicz, } \\
2001\end{array}$ & $\begin{array}{l}\text { Główne gałęzie produkcji przemysłowej: przemysł energetyczny, przemysł } \\
\text { metalurgiczny, przemysł elektromaszynowy, przemysł chemiczny, przemysł } \\
\text { mineralny, przemysł drzewno-papierniczy, przemysł lekki } \\
\text { Czynniki lokalizacji przemysłu } \\
\text { Charakterystyka polskiego przemysłu na tle przemysłu europejskiego }\end{array}$ \\
\hline Dudek 2000 & $\begin{array}{l}\text { USA - światowa potęga gospodarcza } \\
\text { Japonia - cud gospodarczy w kraju klęsk żywiołowych }\end{array}$ \\
\hline Dudek, Wójcik 2004 & $\begin{array}{l}\text { Przemysł elektroenergetyczny i jego rola w gospodarce } \\
\text { Okręi przemysłowe } \\
\text { Współczesne problemy przemysłu }\end{array}$ \\
\hline Plit 1999 & $\begin{array}{l}\text { Afryka - gospodarka } \\
\text { Ameryka Południowa - gospodarka } \\
\text { Gospodarcze wykorzystanie oceanów }\end{array}$ \\
\hline Zając 1999 & Wykorzystanie środowiska do produkcji pozarolniczej \\
\hline Więckowski 2002 & Przemysł i budownictwo w Polsce na przełomie wieków \\
\hline $\begin{array}{l}\text { Walczak, Witek- } \\
\text { Nowakowska } 2002\end{array}$ & Współczesne tendencje zmian rozwoju przemysłu na świecie \\
\hline
\end{tabular}


Tabela 3. Tematyka z geografii przemysłu w wybranych podręcznikach geografii do szkoły ponadgimnazjalnej

\begin{tabular}{|c|c|}
\hline Podręcznik & \begin{tabular}{|c|} 
Treści z geografii przemyslu \\
\end{tabular} \\
\hline $\begin{array}{l}\text { Kop, Kucharska, Szkurłat } \\
2003\end{array}$ & $\begin{array}{l}\text { Wczoraj i dziś polskiego przemysłu } \\
\text { Globalizacja a przemysł } \\
\text { Restrukturyzacja - co to znaczy } \\
\text { Silikonowy świat }\end{array}$ \\
\hline $\begin{array}{l}\text { Krynicka-Tarnacka, Wnuk, } \\
\text { Wojtkowicz } 2002\end{array}$ & $\begin{array}{l}\text { Funkcje i czynniki lokalizacji przemysłu } \\
\text { Przemysł nowych technologii } \\
\text { Przemysł w Polsce na tle krajów Europy }\end{array}$ \\
\hline $\begin{array}{l}\text { Krynicka-Tarnacka, Wnuk, } \\
\text { Wojtkowicz } 2004\end{array}$ & $\begin{array}{l}\text { Przemysł } \\
\text { Charakterystyka wybranych branż przemysłu przetwórczego w Polsce }\end{array}$ \\
\hline Makowska 2002 & $\begin{array}{l}\text { Przemysł przetwórczy i czynniki jego lokalizacji } \\
\text { Regiony intensywnego rozwoju nowoczesnych gałęzi przemysłu } \\
\text { Przestrzenne i społeczne aspekty transformacji przemysłu na świecie } \\
\text { Energetyka obecnie i w przyszłości }\end{array}$ \\
\hline Mordawski, Wiecki 2002 & $\begin{array}{l}\text { Surowce i ich rola w gospodarce } \\
\text { Przemysł - jego funkcje, podział i rozmieszczenie }\end{array}$ \\
\hline Mordawski, Wiecki 2003 & $\begin{array}{l}\text { Górnictwo i kopalnictwo oraz przetwórstwo przemysłowe } \\
\text { Wytwarzanie i zaopatrywanie w energię, gaz i wodę } \\
\text { Współczesny stan polskiego przemysłu }\end{array}$ \\
\hline Wład 2001 & $\begin{array}{l}\text { Dlaczego przemysł rozmieszczony jest nierównomiernie } \\
\text { Problemy pozyskiwania oraz wykorzystania energii i surowców na } \\
\text { świecie } \\
\text { Zmiany i obecne zróżnicowanie produkcji przemysłowej świata } \\
\text { Przegląd głównych regionów i okręgów przemysłowych świata }\end{array}$ \\
\hline $\begin{array}{l}\text { Wójcik, Staniów, Staniów } \\
2002\end{array}$ & $\begin{array}{l}\text { Rozwój przemysłu do } 1918 \text { roku } \\
\text { Eksploatacja surowców } \\
\text { Energetyka } \\
\text { Przemysł przetwórczy } \\
\text { Przekształcenia strukturalne przemysłu w Polsce } \\
\end{array}$ \\
\hline
\end{tabular}

Źródło: Opracowanie własne

W analizowanych programach nauczania geografii oraz podręcznikach szkolnych dobór treści zakresu geografii przemysłu odbywa się według następujących kryteriów:

- w układzie regionalnym kontynent-kraj,

- w układzie studiów tematycznych (problemów),

- w układzie struktury dyscypliny - geografii przemysłu.

Dobór treści według kryterium regionalnego występuje głównie na poziomie gimnazjum. Zagadnienia z geografii przemysłu są omawiane przy charakterystyce wybranych regionów - kontynentów (np. Afryka - gospodarka), a zwłaszcza krajów (np. Brazylia problemy przyrodnicze i społeczno-gospodarcze). Daje to okazję do poznania zróżnicowania procesów uprzemysłowienia w skali globalnej i regionalnej. Wybór państw będących przedmiotem analizy wybranych zjawisk i procesów można uznać za dobry krok w kierunku egzemplarycznego nauczania geografii. W charakterystyce państw, a zwłaszcza szczegółowych prezentacji, zaprojektowano bardzo pożądany dominantowy układ treści. A oto przykłady dominantowego ujęcia treści z geografii przemysłu: 
- industrializacja; Anglia kolebkaą przemysłu, Rozwój przemysłu ciężkiego, Zagłębie Ruhry, Gdzie rozwija się przemysł (Czerny M., Czerny A. 2000),

- USA - światowa potęga gospodarcza, Japonia - cud gospodarczy w kraju klęsk żywiołowych (Dudek 2002).

Natomiast w ujęciu studiów problemowych treści z zakresu geografii przemysłu ukazywane są w aspekcie współzależności między poszczególnymi elementami. A oto przykłady takiego doboru treści na poziomie gimnazjum:

- współczesne tendencje zmian rozwoju przemysłu na świecie (Walczak, WitekNowakowska 2002),

- współczesne problemy przemysłu (Dudek, Wójcik 2004),

- wpływ przemysłu na środowisko przyrodnicze (Dobosik, Kardas, Modzelewska 1999),

- wykorzystanie środowiska do produkcji pozarolniczej (Zając 1999),

oraz szkoły ponadgimnazjalnej:

- globalizacja a przemysł (Kop, Kucharska, Szkurłat 2003),

- przemysł w Polsce na tle krajów Europy (Krynicka-Tarnacka, Wnuk, Wojtkowicz 2002),

- przestrzenne i społeczne aspekty transformacji przemysłu (Makowska 2002),

- dlaczego przemysł rozmieszczony jest nierównomiernie (Wład 2001),

- przekształcenia strukturalne przemysłu w Polsce (Wójcik, Staniów, Staniów 2003.

Taki dobór i układ treści ukazuje przemiany zachodzące w rozwoju przemysłu i czynniki je warunkujące. Stwarza okazję do kształtowania umiejętności obserwacji, analizy oraz formułowania zależności między rozwojem handlu i przemysłu oraz powiązań zachodzących we współczesnej gospodarce w skali lokalnej, regionalnej i globalnej.

Z kolei dobór treści według kryterium struktury dyscypliny - geografii przemysłu dostarcza dużej ilości wiedzy, ale w ujęciu encyklopedycznym. Niektórzy autorzy programów nauczania i podręczników treści z geografii przemysłu prezentują poprzez charakterystykę poszczególnych gałęzi (tab. 2,3) oraz ukazują historię rozwoju przemysłu na ziemiach polskich. Ten dobór treści występuje szczególnie przy prezentowaniu treści z geografii przemysłu w Polsce (III klasa gimnazjum, II/III klasa ponadgimnazjalna). Jest to podejście niezgodne z współczesnymi trendami w dydaktyce geografii. Nie sprzyja ono kształtowaniu umiejętności uczniów oraz postaw.

Rekapitulując należy stwierdzić, iż treści z geografii przemysłu stanowią jeden z elementów geografii społeczno-gospodarczej w nowych programach nauczania i podręcznikach szkolnych. W doborze i układzie treści z geografii przemysłu zawiera się wiele nowych rozwiązań: podejście egzemplaryczne, dominanty regionalne oraz podejście problemowe ukazujące ważną społecznie tematykę związaną z działalnością przemysłową wynikająca $\mathrm{z}$ procesów integracji i globalizacji.

\section{Literatura}

Czerny M., Czerny A., 2000, Zagadnienia społeczne i gospodarcze świata. Moduł 3 dla gimnazjum, Nowa Era, Warszawa.

Dobosik B., Kardas K., Modzelewska B., 1999, Przestrzeń geograficzna, w której żyje człowiek. Podręcznik geografii do gimnazjum, Wyd. SOP, Toruń.

Dudek E., 2003, Geografia 2. Podręcznik dla klasy drugiej gimnazjum, Wyd. Wiking, Wrocław.

Dudek E., Wójcik J., 2003, Geografia. Podręcznik dla klasy trzeciej gimnazjum. Geografia Polski, Wyd. Wiking, Wrocław. 
Kop J., Kucharska M., Szkurłat E., 2003, Geografia, cz. 2. Podręcznik dla szkót ponadgimnazjalnych, Wyd. Szkolne PWN, Warszawa-Lódź.

Krynicka-Tarnacka T., Wnuk G., Wojtkowicz Z., 2001, Moje miejsce w Polsce i regionie. Podręcznik geografii dla gimnazjum cz. 3, Wyd. SOP, Toruń.

Krynicka-Tarnacka T., Wnuk G., Wojtkowicz Z., 2002, Geografia. Człowiek gospodarzem przestrzeni geograficznej. Podręcznik dla liceum ogólnokształcacego, liceum profilowanego i technikum. Zakres podstawowy, cz. 2, Wyd. SOP, Torun.

Krynicka-Tarnacka T., Wnuk G., Wojtkowicz Z., 2003, Geografia Polski dla uczniów szkót ponadgimnazjalnych, Wyd. SOP, Torun.

Liszewski S., 1999, Rola geografii w procesie edukacji spoteczeństwa polskiego na przestrzeni dziejów, [w:] Nauki geograficzne a edukacja społeczeństwa. T. 1. Problemy nauczania geografii. Materiały 48 Zjazdu PTG Łódź 9-11 września, Łódź.

Makowska D. (red.) 2002, Geografia. Podręcznik dla liceum ogólnoksztatcqcego, liceum profilowanego i technikum. Zakres podstawowy, WSiP, Warszawa.

Mordawski J., Wiecki W., 2002, Geografia 2. Zakres podstawowy. Podręcznik dla liceum ogólnokształcacego, liceum profilowanego i technikum. Wyd. Operon, Gdynia.

Mordawski J., Wiecki W., 2003, Geografia 3. Geografia Polski. Zakres podstawowy. Podręcznik dla liceum ogólnoksztatcacego, liceum profilowanego i technikum, Wyd. Operon, Gdynia.

Plit F., 1999, Geografia. Podręcznik dla gimnazjum, WSiP, Warszawa.

Piskorz S., 1999, Edukacja geograficzna w gimnazjum i liceum profilowanym na tle dotychczasowego stanu, [w:] Nauki geograficzne a edukacja społeczeństwa. T. 1. Problemy nauczania geografii. Materiały 48 Zjazdu PTG Łódź 9-11 września, Łódź.

Podstawa programowa ksztatcenia ogólnego, Dz. U. Nr 61 z 2002 r.

Pulinowa M.Z., 2005, Zakres wiedzy geograficznej w edukacji szkolnej, [w:] J. Jania, A. Jankowski (red.), Wpływ rozwoju nauk geograficznych na proces ksztatcenia społeczeństwa oraz promocje wiedzy geograficznej w Polsce. II Forum Geografów polskich, Sosnowiec.

Walczak M., Witek-Nowakowska A., 2002, Wędrówki geograficzne. Podręcznik dla klasy II gimnazjum, PWN, Warszawa.

Wład P., 2001, Geografia 2. Człowiek na Ziemi, jego życie i działalność, Wyd. Ortus., Raszyn

Wójcik J., Staniów H., Staniów P., 2002, Geografia 3. Polska, Wyd. Atlas-Książnica, Katowice.

Zając S., 1999, Geografia Polski. Podręcznik dla gimnazjum, WSiP, Warszawa.

\section{Industrial geography issues in secondary schools geography syllabuses, selected teaching programmes and textbooks}

This research employed the comparative analysis method in order to determine the range of industrial geography issues in secondary schools geography teaching programmes and textbooks. The aim of the research was to identify the factors that determine the choice and presentation methods of topics in industrial geography. The quantitative and qualitative analysis was conducted on the basis of a query of currently used state-approved teaching programmes and textbooks in geography for secondary schools (gymnasium, general, specialized, and technical secondary schools). In total, 15 programmes and 15 textbooks were analysed at the level of lower-secondary school, and 10 programmes and 10 textbooks at the level of upper-secondary schools.

Generally, the issues in industrial geography are included in the II- and III-form programmes of both lower- and upper-secondary schools. The amount of time that the teacher can devote to industrial geography topics is rather small, and most often equals from 1 to 3 classes. Therefore it is crucial that the syllabuses and textbooks treat these issues in accordance with the contemporary trends in geography teaching methodology and with the industrial geography scientific state of the art. This article investigates how these assumptions are realized in relation to the industrial geography issues in the syllabuses, teaching programmes and textbooks. 